\title{
Amphetamine Primes Motivation to Gamble and Gambling- Related Semantic Networks in Problem Gamblers
}

\author{
Martin Zack ${ }^{*, 1,2}$ and Constantine X Poulos ${ }^{1,3}$ \\ 'Centre for Addiction and Mental Health, Toronto, Ontario, Canada M5S 2SI; ' ${ }^{2}$ Departments of Pharmacology and Public Health Sciences, \\ University of Toronto, Toronto, Ontario, Canada M5S IA8; ${ }^{3}$ Department of Psychology, University of Toronto, Toronto, Ontario, Canada M5S 3 G3
}

\begin{abstract}
Previous research suggests that gambling can induce effects that closely resemble a psychostimulant drug effect. Modest doses of addictive drugs can prime motivation for drugs with similar properties. Together, these findings imply that a dose of a psychostimulant drug could prime motivation to gamble in problem gamblers. This study assessed priming effects of oral D-amphetamine (AMPH) $(30 \mathrm{mg})$ in a within-subject, counter-balanced, placebo-controlled design in problem gamblers $(n=10)$, comorbid gamblerdrinkers $(n=6)$, problem drinkers $(n=8)$, and healthy controls $(n=12)$. Modified visual analog scales assessed addictive motivation and subjective effects. A modified rapid reading task assessed pharmacological activation of words from motivationally relevant and irrelevant semantic domains (Gambling, Alcohol, Positive Affect, Negative Affect, Neutral). AMPH increased self-reported motivation for gambling in problem gamblers. Severity of problem gambling predicted positive subjective effects of AMPH and motivation to gamble under the drug. There was little evidence that AMPH directly primed motivation for alcohol in problem drinkers. On the reading task, AMPH produced undifferentiated improvement in reading speed to all word classes in Nongamblers. By contrast, in the two problem gambler groups, AMPH improved reading speed to Gambling words while profoundly slowing reading speed to motivationally irrelevant Neutral words. The latter finding was interpreted as directly congruent with models, which contend that priming of addictive motivation involves a linked suppression of motivationally irrelevant stimuli. This study provides experimental evidence that psychostimulant-like neurochemical activation is an important component of gambling addiction.
\end{abstract}

Neuropsychopharmacology (2004) 29, 195-207, advance online publication, 22 October 2003; doi: | 0.1 038/sj.npp. I 300333

Keywords: amphetamine; gambling; psychomotor stimulants; memory activation

\section{INTRODUCTION}

Problem gambling is often characterized as a behavioral addiction (Ibanez et al, 2003; Potenza, 2001). Like substance addictions, problem gambling is thought to involve disturbances in neurochemical function. In line with this, correlational studies have found anomalies in a number of neurochemical systems in problem gamblers, including dopamine, norepinephrine, and serotonin (Bergh et al, 1997; Moreno et al, 1991; Roy et al, 1988). To date, no research appears to have used a pharmacological probe within a controlled experimental framework to assess neurochemical processes underlying problem gambling.

The motivation to engage in appetitive behavior in general, including psychoactive drug use, can be primed by exposure to a dose of the target reinforcer (Cornell $e t a l$,

\footnotetext{
* Correspondence: M Zack, Centre for Addiction and Mental Health, 33 Russell Street, Toronto, Ontario, Canada M5S 2SI, Tel: $416535-$ 850I, ext. 6052, Fax: 416595 66I8, E-mail: martin_zack@camh.net Received 26 June 2003; revised 12 September 2003; accepted 16 September 2003

Online publication: 17 September 2003 at http://www.acnp.org/ citations/Npp09170303279/default/pdf
}

1989; Duarte et al, 2003; Le et al, 1998; Leri and Stewart, 2001; Shalev et al, 2002). In a seminal study, Konorski (1967) trained dogs to perform two different responses, one for food and one for water. When the animals were later tested while both hungry and thirsty, a priming dose of food led to the food-seeking response whereas a priming dose of water led to the water-seeking response. This finding demonstrates the motivational specificity of priming effects.

Psychoactive drugs are widely used as primes to assess addictive motivation. Drug priming specifically refers to the case in which the noncontingent delivery of a pharmacological agent activates or reinstates a previously established drug-seeking or drug-taking response (Stewart and de Wit, 1987). Like drug reinforcers, gambling has been found to produce priming-like effects in problem gamblers. For example, exposure to a brief gambling episode is associated with greater reported desire to gamble and loss of control over gambling in problem $v s$ nonproblem gamblers (Loba et al, 2001). Also, in a laboratory-based setting, problem gamblers' monetary risk behavior (wagering) escalates over the course of trials during a gambling episode (Ladouceur et al, 1986, 1987, 1991). These findings indicate that, like drugs of abuse in drug abusers, exposure to gambling 
activity can activate motivation to gamble and gambling behavior in problem gamblers.

A common process implicated in drug priming is the release of dopamine in the nucleus accumbens (eg Self and Nestler, 1998; Shaham and Stewart, 1996). However, the degree of priming is also strongly affected by the degree of commonality between the prime and target drugs. Drugs from the same class as the target drug are often effective primes (eg amphetamine (AMPH) for cocaine) whereas drugs from a different class than the target (eg THC for cocaine) usually are not (Schenk and Partridge, 1999; Shalev et al, 2002; Spealman et al, 1999). Thus, drug priming appears to involve both a common process and a specific process or processes, related to the particular neurochemical effects of the target reinforcer.

A number of findings suggest that gambling can induce effects that closely resemble a psychostimulant drug effect. Problem gamblers use strikingly similar language to describe a bout of gambling as psychostimulant abusers use to describe the effects of their drug use (eg arousal, excitement, increased concentration, elevated confidence) (Hickey et al, 1986). The profile of an episode of gambling and psychostimulant use is also similar in that both are characterized by marked behavioral perseveration (Dickerson et al, 1987; Ridley et al, 1988). Neuroimaging research further indicates that anticipation or receipt of money induces selective patterns of activation in brain dopamine pathways (Knutson et al, 2001). These pathways are also critically involved in the reinforcing effects of psychostimulant drugs (Mackey and van der Kooy, 1985; Spyraki et al, 1982; Yokel and Wise, 1978).

These kinds of evidence imply that a psychostimulant drug may recruit a set of effects similar to those recruited by gambling itself. If so, a dose of a psychostimulant drug may serve to prime motivation to gamble much like a 'dose' of gambling. To assess this possibility, we employed the prototypic psychostimulant, D-AMPH, as a pharmacological prime in problem gamblers and Nongambler controls.

To test the selectivity of AMPH's priming effects we also examined the drug's effects on motivation for alcohol in problem drinkers. To date, no research appears to have examined such potential priming effects of AMPH in this population. In healthy volunteers, alcohol itself can induce both stimulant and sedative effects (Boerngen-Lacerda and Souza-Formigoni, 2000; King et al, 2002; Martin et al, 1993; Schechter and Lovano, 1982). Correlational evidence also indicates some correspondence in the subjective effects of alcohol and AMPH in healthy volunteers (Holdstock and de Wit, 2001). Nevertheless, alcohol's most pronounced and consistent subjective effects are sedative (Holdstock and de Wit, 1998, 2001; Schuckit et al, 1991; Walsh et al, 1991) consistent with its designation as a CNS depressant, whereas AMPH's primary effects are stimulant (de Wit et al, 2002; Heishman and Henningfield, 1991; Zacny et al, 1992). Research with animals further indicates that the discriminative stimulus properties of alcohol are unlike those of AMPH (Druhan et al, 1991). The AMPH stimulus primarily involves mono-amine activation (Brauer et al, 1997; Furmidge et al, 1991; Ranaldi et al, 2000; Sasaki et al, 1995), whereas the alcohol stimulus primarily involves GABA-A activation and glutamate inhibition (Jackson et al, 2003; Kostowski and Bienkowski, 1999; Shelton and Grant,
2002; Stolerman and Olufsen, 2001), along with some serotonergic elements (Maurel et al, 1997). In animal studies, systemic AMPH, at a range of doses, does not reliably prime alcohol seeking in animals familiar with alcohol (Halladay et al, 1999; Hubbell et al, 1991; Linseman, 1990), but consistently primes seeking of another psychostimulant - cocaine - in animals familiar with cocaine (de Wit and Stewart, 1981; Lynch et al, 1998; Schenk and Partridge, 1999). ${ }^{1}$ Based on these animal findings, we would not expect AMPH to prime motivation for alcohol in problem drinkers. To further assess this issue, we also included a group of problem gamblers with concurrent alcohol problems in the present design. In line with previous studies (Loba et al, 2001; Krystal et al, 1994), motivation to gamble and motivation for alcohol were assessed by means of self-report using modified visual analog scales.

To further examine processes involved in the effects of AMPH, we also incorporated a task that assessed activation of gambling-related memory networks or semantic domains. A strategy widely used to assess activation of memory networks is the semantic priming procedure (Neely, 1991). Semantic priming is defined as an improvement in reaction time (ie key press or vocal reading response) to a target word (eg doctor) when it is preceded by a semantically related prime word (eg nurse) relative to a semantically unrelated prime word (eg peach) (Ellis and Hunt, 1993, p 60). Variants of this task have also been used in addiction research (Weingardt et al, 1996; Weinstein et al, 2000; Zack et al, 1999).

Primed motivation to engage in addictive behavior has been linked with increased 'incentive salience' of target reinforcers (Robinson and Berridge, 1993, 2001). From a cognitive science perspective, salience involves selective activation of concepts related to the target reinforcer in memory (Bower, 1981; Volkow et al, 2002). Such activation should be directly measurable in terms of faster access to motivationally relevant $v s$ motivationally irrelevant concepts. To test this hypothesis, we modified the conventional semantic priming task to assess direct drug-induced priming of addictive memory networks. Thus, while a verbal associate serves as the prime in conventional semantic priming procedures, in the present study, AMPH served as the priming stimulus for activation of motivationally relevant words. A voice-activated computerized task measured reading speed (ms) to gambling-related target words and words from several other categories under AMPH and placebo, but in the absence of any preceding verbal primes. On any given trial, subjects simply saw a ready signal and responded to the subsequent target word as quickly as possible. This procedure represents a melding of two established methodologies: pharmacological priming and semantic priming. To distinguish this procedure from conventional semantic priming tasks, we refer to it as the Lexical Salience Task.

\footnotetext{
${ }^{1}$ At some doses, microinjections of amphetamine into the nucleus accumbens have been found to increase drinking behavior in rats, primarily by altering the processes that normally serve to regulate drinking cessation rather than the processes that serve to prime alcohol seeking or to initiate drinking (Samson et al, 1999).
} 
It was predicted that AMPH would significantly increase motivation to gamble in problem gamblers. This would be evident in self-reported motivation to engage in gambling and by faster response time (RT) to gambling-related (eg wager) $v s$ motivationally irrelevant, neutral words (eg window) on the Lexical Salience Task. AMPH was not expected to prime motivation for alcohol in problem drinkers.

\section{MATERIALS AND METHODS}

\section{Study Overview and Design}

A double-blind, placebo-controlled, counter-balanced, between-within design was employed. The between-subjects variables were Gambler Status (Gambler, Nongambler) and Drinker Status (Drinker, Nondrinker). These variables were fully crossed, resulting in four cells: Gambler Nondrinkers (G; $n=10)$, GamblerDrinkers (GD; $n=6)$, Drinker Nongamblers $(\mathrm{D} ; n=10)$, and Nongambler Nondrinker Controls $(\mathrm{C} ; n=12)$. $^{2}$

The within-subjects variable was Treatment: AMPH vs placebo. Order of Treatment was randomly counterbalanced across subjects (Ss). Ss attended four sessions in all: A drug screening and interview, physician's exam, and two procedurally identical test sessions, 1 week apart. They received $\$ 500$ for participation.

\section{Subjects}

Ss ( 11 females, 25 males), ages $21-58$ years $(M=36.6)$, were recruited by newspaper advertisements. All were drug- and medication-free. Ss with a history of mental illness, apart from problem gambling or drinking, including learning disabilities or attention deficit hyperactivity disorder, were excluded from the study. Detailed subject characteristics are provided in the Results section.

\section{Apparatus and Materials}

A score $\geqslant 5$ on The South Oaks Gambling Screen (SOGS; Lesieur and Blume, 1987) defined problem gambling; a score $<4$ defined nonproblem gambling. ${ }^{3}$ The maximum loss (\$) in a single gambling episode (Max-Loss) served as a behavioral index of problem gambling severity. These two indices of problem gambling severity correlated at $r=0.71$, $p<0.001$. A score $\geqslant 9$ on The Alcohol Dependence Scale (ADS; Ross et al, 1990) defined problem drinking; a score $<8$ defined nonproblem drinking. The Timeline Followback (TLFB; Sobell and Sobell, 1992) measured alcohol use in the 90 days preceding screening. Drinks per week provided a behavioral index of problem drinking severity.

\footnotetext{
${ }^{2}$ The terms Nongambler and Nondrinker were used for brevity. Some subjects (Ss) who were designated as Nongamblers (ie Groups D, C) gambled socially (no evidence of problem gambling) and all Ss designated as Nondrinkers (ie Groups G, C) drank socially (no evidence of problem drinking)

${ }^{3}$ In Group G, five Ss reported casino games (slot machines, cards) as their predominant form of gambling; four said they engaged in multiple forms of gambling (casino, racetrack, sports lottery, bingo); and one primarily played bingo. In Group GD, two Ss endorsed multiple forms; two endorsed sports lottery; while casino and bingo were each endorsed by one $\mathrm{S}$.
}

Ss were naïve to the effects of psychomotor stimulants as determined by self-report and a score $<5$ on the Drug Abuse Screening Test (DAST; Skinner, 1982). Ss were not clinically depressed: scores $<8$ on the short form of the Beck Depression Inventory (BDI; Beck and Beck, 1972). The Eysenck Personality Inventory (EPI; Eysenck and Eysenck, 1963) measured Extraversion and Neuroticism.

During test sessions, a modified version of the Multiple Affective Adjective Checklist (MAACL; Zuckerman and Lubin, 1965) measured Ss' global affective state on five subscales: Anxiety, Depression, Hostility, Positive Affect, and Sensation Seeking. The checklist was modified to provide a graduated rating of current affect (0-4; Not at AllExtremely) for each adjective.

Modified visual analog scales measured the subjectivemotivational effects of AMPH and placebo. Ss reported the extent to which they agreed (0-4; Not at All-Completely) with each of seven statements, based on their current feelings during the test sessions. The statements were as follows: (a) Right now, I am feeling the good effects of the medication. (b) I like this medication. (c) Right now, I am feeling the bad effects of the medication. (d) I dislike this medication. (e) I would like to take this medication again.(f) Right now, I would like to go gambling. (g) Right now, I would like to drink some alcohol.

Using wording from The Situational Confidence Questionnaire (SCQ; Annis and Graham, 1988) Ss provided two additional ratings: confidence $(0-100 \%$; Not at All-Completely) to resist gambling Right now, if there were a casino across the street, and to resist drinking Right now, if there were a bar across the street.

The Lexical Salience Task (see below) was administered on a PC, programmed in MicroExperimental Laboratories (MEL, v. 2.01; Schneider, 1988), and run entirely within MSDOS. A microphone, held in place by a gooseneck clamp and attached to the computer by a cable, measured vocal reading speed (ie onset of the vocal response). The computer recorded Ss' responses with millisecond accuracy. A serial response box (Psychology Software Tools, Pittsburgh, PA), also attached to the computer by cable, enabled on-line coding of response accuracy.

Blood pressure and heart rate were measured by an unobtrusive wrist cuff (Model HEM-601, Omron Inc., Vernon Hills, IL) attached above the S's nondominant hand. Ss could not see the readings from the device, precluding possible reactivity to this information.

\section{Activation of Semantic Domains: The Lexical Salience Task}

Five categories of word stimuli were employed in the Lexical Salience Task, with 30 items in each category: Gambling, Alcohol, Positive Affect, Negative Affect, and Neutral. The items for each category are shown in the appendix. Gambling words were drawn from previous research on cognitive biases in problem gamblers (McCusker and Gettings, 1997) with supplemental items generated based on face validity (eg jackpot). Alcohol words were drawn from previous research on cognitive biases in problem drinkers (Stetter et al, 1995; Zack et al, 1999). Positive Affect items were derived from items on The Profile of Mood States (Shacham, 1983) and the stimulant subscales of the 
Addiction Research Center Inventory (Haertzen, 1965). Negative Affect items were derived from previous research with anxious and depressed nonproblem gamblers and drinkers (Bradley and Mathews, 1983; Mogg et al, 1995). Neutral items were the names of parts of a building drawn from a compendium of word frequency norms (Battig and Montague, 1969). There were no differences in the mean length, number of syllables, first letter, or frequency of occurrence in print of the words across the five categories. This controlled for the possible influence of these nonsemantic moderators of memory activation.

As indicated in the Introduction, the Lexical Salience Task was a version of the rapid reading task, modified to assess the effect of a pharmacological prime rather than a semantic prime on activation of motivationally relevant concepts (eg gambling, alcohol) vs motivationally irrelevant (ie neutral) concepts in memory. Thus, individual word targets were administered without any verbal primes. Vocal reading RT (ms) to target words was the dependent variable.

To maximize priming effects, target words were degraded with asterisks (eg $\mathrm{w}^{\star} \mathrm{a}^{\star} \mathrm{g}^{\star} \mathrm{e}^{\star} \mathrm{r}$ ) (Stanovich and West, 1983; Weingardt et al, 1996). The task parameters also conformed to those of conventional semantic priming studies (Neely, 1991). The task administered 20 practice trials and 150 (5 categories $\times 30$ stimuli/category) test trials. Items from the five categories were randomly distributed over test trials. The items for the practice trials were fruit words (eg $\left.a^{*} p^{\star} p^{*} l^{\star} e\right)$. The sequence of events on each trial was identical. A focus stimulus ( $\& \& \& \& \&)$ appeared in the center of the screen for $350 \mathrm{~ms}$ to orient attention to target location. The focus stimulus was followed by a blank screen $(200 \mathrm{~ms})$, after which the target appeared in the same location. The target remained on the screen until $S$ responded. The interval between target offset and onset of the next focus stimulus was $550 \mathrm{~ms}$.

During the task, $S$ faced the computer screen at a distance of $60 \mathrm{~cm}$. The stimuli were $0.5 \mathrm{~cm}$ in height and appeared in white against a black background. An experimenter, seated behind S, recorded response accuracy (correct, misread) after every trial by means of the serial response box.

\section{Procedure}

The study was carried out in compliance with ethical principles of the Helsinki Declaration (1975). Prior to participation, S signed a consent form, outlining the study requirements and confirming confidentiality and ethics approval of the study by the IRB of the Centre for Addiction and Mental Health.

Ss were instructed to abstain from caffeine and alcohol for $12 \mathrm{~h}$ prior to the start of each session, and to fast on the mornings of their test sessions. The sequence of events was identical on each test session. Upon arrival at the laboratory (0845), $S$ received a breathalyzer test to confirm she/he was alcohol-free. A baseline reading of heart rate and blood pressure was taken at this time, and at 30-min intervals thereafter until $\mathrm{S}$ was dismissed. At 0900 , $\mathrm{S}$ received a standard breakfast designed to minimize variability in the absorption of AMPH. A visually identical capsule containing $30 \mathrm{mg}$ D-AMPH or placebo was administered with breakfast on each session. $S$ read magazines in a quiet waiting room while the dose was being absorbed.

$S$ began the Lexical Salience Task 90 min after dosing, at which time the subjective-behavioral effects of oral AMPH are maximal (Brauer et al, 1996). Upon completion of the task (3-5 min), $S$ completed the modified visual analog scales and the MAACL.

\section{Data Analytic Plan}

Gender effects were analyzed by $\chi^{2}$. Continuous data were analyzed by analysis of variance (ANOVA). In cases where significant between-group differences emerged under placebo, analyses of covariance (ANCOVA) were conducted with placebo responses as the covariate. In cases where multiple indices assessed a particular construct (eg positive subjective effects; negative subjective effects), multivariate analyses of variance (MANOVAs) were first performed. Significant multivariate interactions were followed up with univariate ANOVAs. Significant ANOVA interactions were investigated by simple effects analyses (Winer, 1971). Complementary correlational analyses assessed the relationship between self-reported positive, negative, and motivational effects of AMPH and indices of the severity of problem gambling and problem drinking. A parallel set of analyses assessed the correlation between reading speed to Gambling words, Alcohol words, and Neutral control words, and the indices of addictive severity. Possible mediator effects were controlled in these analyses by partial correlation.

In line with standard procedure in studies using rapid reading methodology (Neely, 1991), scores greater than 2.5 SDs from the mean of a given word condition were designated as outliers, and excluded from subsequent analyses. Errors (ie misreading target words) were also excluded from the RT analyses. Preliminary ANOVAs confirmed that the frequency of outliers $(M=2.2$ of 30 trials) and errors $(M=2.0$ of 30 trials $)$ did not vary as a function of Gambler Status, Drinker Status, or Treatment (drug vs placebo).

\section{RESULTS}

\section{Subject Characteristics}

Table 1 reports the mean (SD) subject characteristics scores for all four groups. A two-way $\chi^{2}$ found no difference in the gender ratio ( $44 \%$ female) of the four groups, $p>0.94$. A series of 2 (Gambler Status) $\times 2$ (Drinker Status) ANOVAs compared the groups on each continuous variable. The table shows that there were no significant group differences in mean age, $p$ 's $>0.08$. A main effect of Gambler Status on the SOGS confirmed that severity of problem gambling was significantly greater in Gambler groups $(G, G D)$ than in Nongambler groups $(D, C), F(1,32)=97.73, p<0.0001$. The lack of interaction in this analysis, $p>0.49$, indicated that severity of problem gambling did not differ between Groups G and GD nor between Groups D and C. A main effect of Gambler Status also emerged for Max-Loss, $\mathrm{F}(1,32)=118.74, p<0.0001$, together with an absence of other significant effects, $p$ 's $>0.18$. Thus, the maximum loss in a single gambling episode (Max-Loss) reliably 
Table I Mean (SD) Subject Characteristics for Gamblers (G; $n=10)$, GamblerDrinkers (GD; $n=6)$, Drinkers (D; $n=8)$, and Controls $(C ; n=12)^{a}$

\begin{tabular}{|c|c|c|c|c|}
\hline & \multicolumn{4}{|c|}{ Group } \\
\hline & G & GD & D & C \\
\hline \multirow[t]{2}{*}{ Age (years) } & 32.6 & 40.8 & 39.5 & 35.8 \\
\hline & $(11.1)$ & $(9.6)$ & $(\mid 1.3)$ & $(7.0)$ \\
\hline Gender (M:F) & $7: 3$ & $4: 2$ & $5: 3$ & $9: 3$ \\
\hline \multirow{2}{*}{ SOGS } & $8.4 *$ & $8.0 *$ & 0.6 & 0.2 \\
\hline & (3.4) & (3.3) & $(1.1)$ & $(0.4)$ \\
\hline \multirow[t]{2}{*}{ Max-Loss ${ }^{b}$} & 1578* & $2008^{*}$ & 325 & 0 \\
\hline & $(|65|)$ & (3928) & $(9 \mid 9)$ & $(0)$ \\
\hline \multirow[t]{2}{*}{ ADS } & 4.6 & $12.2 *$ & |4.3* & I.I \\
\hline & (3.9) & $(6.7)$ & $(9.3)$ & $(1.8)$ \\
\hline \multirow[t]{2}{*}{ Drinks/week } & 4.4 & $30.5 *$ & $35.1 *$ & 1.6 \\
\hline & $(4.1)$ & $(15.0)$ & $(16.3)$ & $(2.5)$ \\
\hline \multirow[t]{2}{*}{ DAST } & 0.5 & 0.2 & 0.9 & 0.3 \\
\hline & $(0.5)$ & $(0.4)$ & $(1.5)$ & $(0.7)$ \\
\hline \multirow[t]{2}{*}{$\mathrm{BDI}$} & 3.8 & $4.7^{*}$ & $5.5^{*}$ & 0.6 \\
\hline & (3.8) & $(2.9)$ & $(4.6)$ & $(1.0)$ \\
\hline \multirow[t]{2}{*}{ EPI-E } & 14.7 & 12.8 & 11.1 & 13.6 \\
\hline & $(4.9)$ & $(4.6)$ & $(4.3)$ & $(2.6)$ \\
\hline \multirow[t]{2}{*}{ EPI-N } & 9.5 & $12.3^{*}$ & 9.6 & 4.6 \\
\hline & (5.7) & $(6.8)$ & $(7.1)$ & (3.6) \\
\hline
\end{tabular}

aSOGS = South Oaks Gambling Screen score ( $\geqslant 5$ = 'Problem Gambling'); MaxLoss = Maximum loss (\$) in a single gambling episode; ADS = Alcohol

Dependence Scale score $(\geqslant 9=$ 'Problem Drinking'); DAST $=$ score on Drug Abuse Screening Test ( $\geqslant 5=$ problem drug use). BDI = BDI-short form score $(\geqslant 8=$ clinical depression); EPI-E = score on the Eysenck Personality InventoryExtraversion subscale; EPI-N = score on the Eysenck Personality InventoryNeuroticism subscale.

${ }^{\mathrm{b}} \mathrm{A}$ single outlier on Max-Loss, 4.7SD above the mean, led to a significant positive skew in this variable. Therefore, a logarithmic transformation was applied, which negated this effect.

*Significant difference from controls (Group C), $p<0.05$.

distinguished Gamblers from Nongamblers, but did not vary as a function of Drinker Status. ${ }^{4}$

Analyses of problem drinking variables (ADS, drinks/ week) yielded main effects of Drinker Status, F's $(1,32)>28.62, p$ 's $<0.0001$, coupled with no interactions or main effects of Gambler Status, $p$ 's $>0.15$. Thus, severity of problem drinking as assessed by ADS and drinks per week reliably distinguished between Drinkers and Nondrinkers, but did not vary as a function of Gambler Status.

Analysis of DAST scores yielded no significant effects, $p$ 's $>0.14$. Analysis of BDI scores yielded a main effect of Drinker Status, $\mathrm{F}(1,32)=6.79, p=0.014$, and no other significant effects, $p$ 's $>0.07$. Table 1 shows that Drinkers (Groups GD and D) were more depressed than Nondrinkers

\footnotetext{
${ }^{4}$ As noted in the footnotes to Table 1, a single outlier led to a significant positive skew in Max-Loss scores, which was negated by a logarithmic transformation. The present ANOVA assessed the log-transformed MaxLoss scores.
}

(Groups G and C). Analysis of EPI-Extraversion scores yielded no significant effects, $p$ 's $>0.12$. Analysis of EPINeuroticism scores yielded marginal main effects of Drinker Status, $\mathrm{F}(1,32)=4.12, p=0.051$, and Gambler Status, $\mathrm{F}(1,32)=3.86, p=0.058$, but no interaction, $p>0.57$.

\section{Physiological Effects of AMPH}

Heart rate. A 2 (Gambler Status) $\times 2$ (Drinker Status) $\times 2$ (Treatment: AMPH, placebo) $\times 7$ (Time: $0,30,60,90,120$, 150, $180 \mathrm{~min}$ after dosing) ANOVA yielded a Treatment $\times$ Time interaction, $\mathrm{F}(6,192)=14.07, p<0.001$, but no interactions or main effects of Gambler or Drinker Status, $p$ 's $>0.08$. Mean (SD) heart rate rose from 73.9 (9.0) beats/min at dosing to a maximum of 86.0 (13.8) beats $/ \mathrm{min}$ $120 \mathrm{~min}$ after receipt of AMPH. Heart rate tended to decline from 80.3 (6.6) to 77.3 (10.2) beats/min during this interval under placebo.

Blood pressure. A $2 \times 2 \times 2 \times 7$ MANOVA with two measures (systolic/diastolic) assessed blood pressure under AMPH and placebo. The analysis yielded a significant multivariate Treatment $\times$ Time interaction, $\mathrm{F}(12,20)=3.82$, $p=0.004$, and no significant interactions or main effects involving Gambler or Drinker Status, $p$ 's $>0.09$. Mean (SD) blood pressure rose from 124.4/78.7 (8.4/5.4) to 141.1/88.2 (14.4/9.0) $\mathrm{mmHg} 90 \mathrm{~min}$ after receipt of AMPH. In contrast, blood pressure tended to decline from $128.3 / 81.3(7.8 / 7.2)$ to $125.3 / 77.2(15.0 / 10.2) \mathrm{mmHg}$ during this interval under placebo. The lack of interactions among Treatment, Gambler Status, and Drinker Status on heart rate and blood pressure indicates that AMPH had consistent physiological effects in the four groups.

\section{Self-Report Measures}

Multiple Affective Adjective Checklist. A $2 \times 2 \times 2 \times 5$ (Subscale: Anxiety, Depression, Hostility, Positive Affect, Sensation Seeking) ANOVA of the modified MAACL scores yielded no significant Treatment $\times$ Subscale interaction, nor any effects involving Gambler or Drinker Status, $p$ 's $>0.27$. A main effect of Treatment, $\mathrm{F}(1,32)=10.18, p=0.003$, reflected a higher mean overall rating, regardless of Subscale, under drug $(M=1.34, \mathrm{SD}=0.37)$ than placebo $(M=1.13, \quad \mathrm{SD}=0.41) . \quad \mathrm{A}$ main effect of Subscale, $\mathrm{F}(4,128)=172.29, p<0.0001$, reflected higher mean ratings, irrespective of Treatment, on the Positive Affect $(M=2.60$, $\mathrm{SD}=0.72)$ and Sensation Seeking $(M=2.50, \mathrm{SD}=0.85)$ subscales, than on the Anxiety $(M=0.43, \mathrm{SD}=0.48)$, Depression $(M=0.40, \mathrm{SD}=0.45)$, or Hostility $(M=0.27$, $\mathrm{SD}=0.32)$ subscales.

Positive effects. Panels in Figure 1 show the mean (SEM) modified visual analog scale scores for the effects of AMPH and placebo in each group and indicate significant effects.

A $2 \times 2 \times 2 \times 3$ (Measure) MANOVA assessed Good Effects, Liking, and Desire to Take Again. The analysis yielded a multivariate main effect of Treatment, $\mathrm{F}(3,30)=6.05, p=0.002$, and no other significant effects, $p$ 's $>0.30$. Thus, AMPH led to a generally consistent increase in positive subjective effects across the four groups (see panels (a)-(c)). 
Negative effects. A $2 \times 2 \times 2 \times 2$ MANOVA assessed the effects of Treatment on measures of Bad Effects and Disliking. The analysis yielded a multivariate Treatment $\times$ Gambler Status $\times$ Drinker Status interaction, $\mathrm{F}(2,31)=3.92, p=0.030$. Univariate ANOVAs for each measure revealed the source of the interaction. There were no significant effects involving Disliking, $p$ 's $>0.36$, whereas the ANOVA of Bad Effects yielded a Treatment $\times$ Gambler Status $\times$ Drinker Status interaction, $F(1,32)=5.33$, $p=0.028$. Simple effects analyses (Winer, 1971) found that AMPH increased Bad Effects ratings in Group D, $t(32)=4.52, p<0.001$, but did not significantly alter ratings in the other three groups, $p$ 's $>0.06$ (see panels (d) and (e)).

Motivational effects. A $2 \times 2 \times 2 \times 2$ (Desire: Gamble, Alcohol) ANOVA assessed the effects of AMPH on ratings of Desire to Gamble and Desire for Alcohol. The ANOVA yielded a significant four-way interaction, $\mathrm{F}(1,32)=8.52$, $p=0.006$. Simple effects analyses determined that AMPH produced a significant increase in Desire to Gamble in Group $G, t(32)=2.63, p<0.05$, but not in the other three groups, $p$ 's $>0.30$ (panel f). AMPH significantly increased Desire for Alcohol in Group GD, $t(32)=2.19, p<0.05$, but had no significant effects in the other three groups, p's $>0.30$ (panel g).

A preliminary ANOVA revealed significant baseline differences in Confidence to Resist Gambling and Alcohol under placebo. To determine if AMPH differentially affected Confidence to Resist Gambling and Alcohol in Gamblers and Drinkers when baseline differences in these ratings were controlled, two $2 \times 2$ ANCOVAs were conducted on confidence scores under $\mathrm{AMPH}$, using the corresponding confidence scores under placebo as the covariates. The ANCOVA of Confidence to Resist Gambling under AMPH yielded a main effect of Gambler Status, $\mathrm{F}(1,31)=5.18$, $p=0.030$, and no other significant effects, $p$ 's $>0.15$ (panel $\mathrm{h})$. Thus, when baseline differences under placebo were controlled, Gamblers reported significantly lower Confidence to Resist Gambling under AMPH than Nongamblers. The ANCOVA of Confidence to Resist Alcohol under AMPH yielded no significant effects, $p$ 's $>0.19$ (panel i).

Correlational analyses. Pearson partial correlations, controlling for ratings under placebo, assessed the relation between the positive, negative, and motivational effects of AMPH and the indices of problem gambling and problem drinking. ${ }^{5}$ Significant correlations $(p<0.05$, two-tailed) are reported.

The Max-Loss index of problem gambling correlated positively with Good Effects, $r=0.52$, Liking, $r=0.46$, Desire to Take Again, $r=0.53$, and Desire to Gamble, $r=0.44$. Disliking correlated negatively with Max-Loss, $r=-0.46$ and SOGS, $r=-0.45$.

The ADS index of problem drinking correlated negatively with Good Effects, $r=-0.43$, while Drinks per Week

\footnotetext{
5 All correlations in the study were based on scores from noncontrol Ss $(n=24)$. The mean and SD score for control Ss $(n=12)$ on Max-Loss was 0 (see Table 1). Similarly, the modal score for controls was 0 on SOGS $(n=10)$, ADS $(n=8)$, and Drinks per Week $(n=6)$. This led to heavytailed distributions for these indices that could not be normalized by transformation.
}

correlated negatively with Liking, $r=-0.39$, and Desire to Take Again, $r=-0.43$.

\section{Lexical Salience Task and Activation of Semantic Domains}

Baseline reading speed under placebo. A $2 \times 2 \times 5$ ANOVA of RT to the five types of words under placebo yielded a main effect of Word Condition, $\mathrm{F}(4,128)=10.95, p<0.001$, and no other significant effects, $p$ 's $>0.22$. Therefore, between-group differences in reading speed under AMPH do not reflect pre-existing differences under placebo.

Effects of AMPH on reading speed. Table 2 shows the group mean (SD) RT scores for the fiveword conditions under placebo along with the change from placebo induced by AMPH. The table shows that AMPH led to faster RT (positive change scores) in all conditions in the Nongambler groups $(D, C)$. In contrast, both of the Gambler groups $(G$, GD) demonstrated pronounced slowing of RT to Neutral words (negative change scores) under AMPH, coupled with a modest improvement in RT to Gambling words.

A $2 \times 2 \times 2 \times 5$ ANOVA assessed reading $\mathrm{RT}$ to the five types of words under AMPH and placebo. The analysis yielded a significant Gambler Status $\times$ Treatment $\times$ Word Condition interaction, $\mathrm{F}(4,128)=3.76, p=0.006$, and no two-way or higher order Drinker Status $\times$ Treatment interactions, $p$ 's $>0.21$. Figure 2 plots the mean (SEM) difference in reading $\mathrm{RT}$ (placebo minus $\mathrm{AMPH}$ ) for each word condition in Nongamblers and Gamblers, and depicts the three-way interaction.

In Nongamblers, the figure shows that AMPH led to faster reading speed across all word conditions. In these Ss, simple effects comparisons found no reliable differences in the degree of change in reading speed across the fiveword conditions, $p$ 's $>0.30$. Additional individual analyses found that the increase in reading speed under AMPH relative to placebo was significant for each word condition except Alcohol, $p$ 's $<0.05$.

In Gamblers, the figure reveals a markedly different pattern. As predicted, AMPH significantly facilitated reading speed to Gambling words, $t(128)=1.77, p<0.05$, onetailed. In contrast, the drug significantly slowed reading speed to Neutral words, $t(128)=-7.56, p<0.0001$. AMPH did not significantly alter reading speed in the other threeword conditions, $p$ 's $>0.35$.

Correlational analyses. Correlational analyses assessed the relation between reading speed under AMPH to Gambling words, Alcohol words, and Neutral control words and indices of problem gambling and problem drinking. AMPH can have both general and specific effects on RT to diverse stimuli. These analyses were conducted in a manner that isolated the specific effects of AMPH on each class of words (eg Gambling) while controlling, by partial correlation, for its effects on the remaining classes of words.

In line with the hypotheses, a negative correlation emerged between Max-Loss and RT to Gambling words, $r=-0.43, p=0.026$, one-tailed. Thus, the greater the severity of problem gambling, the faster the reading speed to Gambling words under AMPH. RT to Neutral words was 

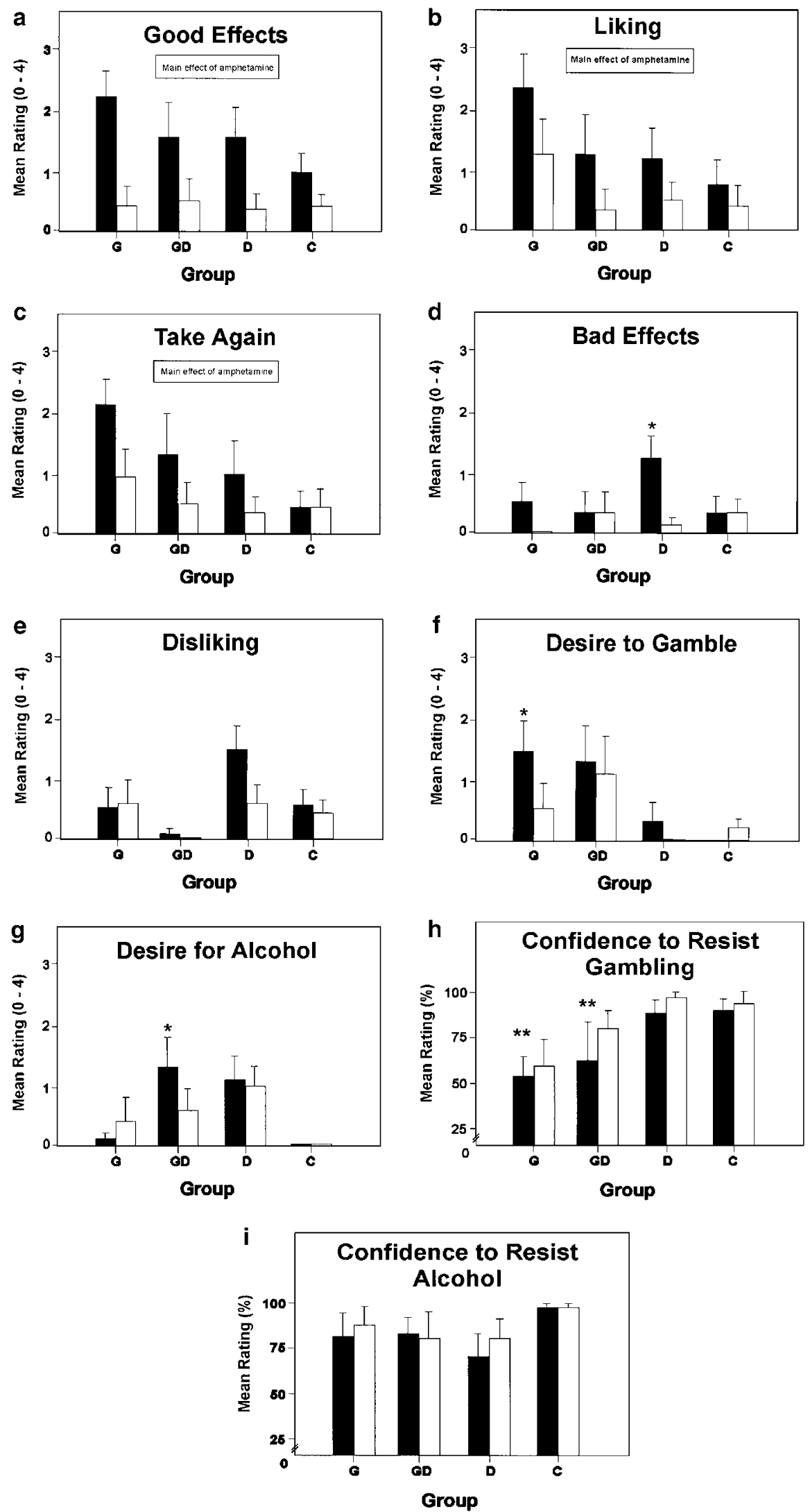

Figure I Mean subjective-motivational effects of amphetamine $(30 \mathrm{mg} ; \mathbf{0})$ and placebo $(\square)$ on modified visual analog scales (0-4: Not at AllCompletely; Confidence to Resist 0-100\%: Not at All-Completely) in problem gamblers (G; $n=10)$, comorbid gamblerdrinkers (GD; $n=6$ ), problem drinkers $(D ; n=8)$, and healthy controls $(C ; n=12)$. *Simple effect of Treatment, AMPH vs placebo, $p<0.05$, two-tailed. **Main effect of Gambler Status (G/GD vs D/C) under AMPH, corrected for placebo by covariance, $p<0.05$, two-tailed. Error bars show SEM. 
Table 2 Group Mean (SD) Reading Response Time (RT; ms) in Fiveword Conditions Under Placebo, and RT Change from Placebo Under $\mathrm{AMPH}(\Delta=$ placebo minus AMPH) for Gamblers (G; $n=10)$, GamblerDrinkers (GD; $n=6)$, Drinkers $(\mathrm{D} ; n=8)$, and Controls (C; $n=12)$

\begin{tabular}{|c|c|c|c|c|c|c|}
\hline \multirow[b]{2}{*}{ Group } & \multirow[b]{2}{*}{ Treatment } & \multicolumn{5}{|c|}{ Word condition } \\
\hline & & Gambling & Alcohol & Positive Affect & Negative Affect & Neutral \\
\hline & $\mathrm{AMPH}-\Delta$ & $9(135)$ & $40(101)$ & $18(99)$ & $17(110)$ & $-39(134)$ \\
\hline GD & Placebo & $853(142)$ & $834(166)$ & $813(128)$ & $800(|4|)$ & 901 (198) \\
\hline \multirow[t]{2}{*}{ D } & Placebo & $711(185)$ & $702(161)$ & $736(170)$ & $684(162)$ & 755 (204) \\
\hline & $\mathrm{AMPH}-\Delta$ & $34(99)$ & $2(113)$ & $32(109)$ & II (103) & $49(100)$ \\
\hline \multirow[t]{2}{*}{ C } & Placebo & $783(160)$ & $767(117)$ & $766(117)$ & $766(122)$ & $806(143)$ \\
\hline & AMPH- $\Delta$ & $37(125)$ & $8(128)$ & $19(106)$ & $29(110)$ & $4(139)$ \\
\hline
\end{tabular}

Positive change $(\Delta)$ scores indicate that AMPH led to faster reading RT relative to placebo. Negative change $(\Delta)$ scores indicate that AMPH slowed reading RT relative to placebo

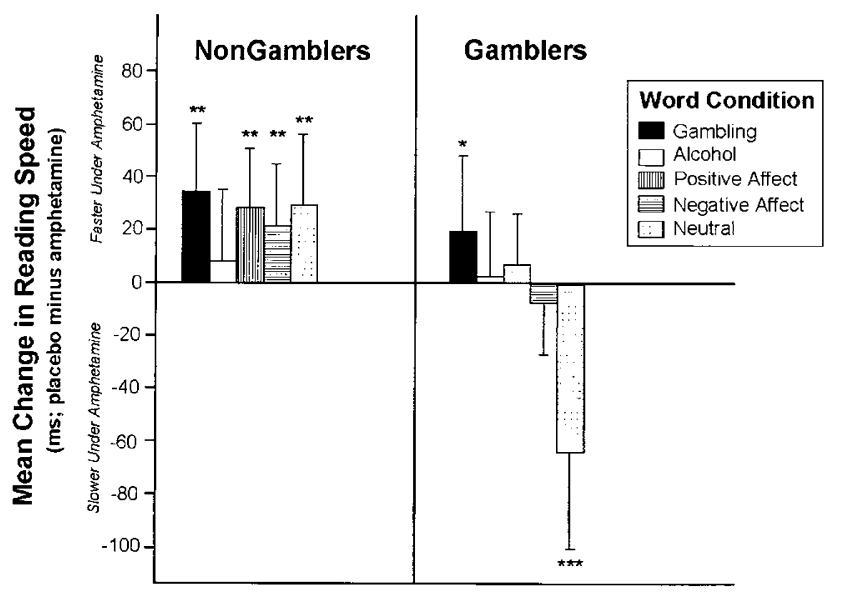

Figure 2 Mean effect of amphetamine $(30 \mathrm{mg})$ on reading speed (ms difference from placebo) to words from five categories: Gambling, Alcohol, Positive Affect, Negative Affect, and Neutral, in nonproblem gamblers $(n=20)$ and problem gamblers $(n=16)$. Positive scores indicate faster reading speed under $\mathrm{AMPH}$ than placebo. Negative scores indicate slower reading speed under $\mathrm{AMPH}$ than placebo. ${ }^{*} p<0.05$, one-tailed; $* * * 0.05$, two-tailed; $* * * * 0<0.0001$, two-tailed.

positively correlated with Max-Loss, $r=0.50, p=0.022$, and SOGS, $r=0.56, p=0.010$. Thus, the greater the severity of problem gambling the slower the reading speed to Neutral words under AMPH. Severity of problem drinking did not correlate reliably with RT to Alcohol, Gambling, or Neutral words, $p$ 's $>0.20$.

To assess the correspondence between the self-report and cognitive indices of motivation, correlations were computed between Desire to Gamble and RT to Gambling words and between Desire for Alcohol and RT to Alcohol words. Correlations controlled for self-report and RT responses under placebo. The correlation between the two indices of gambling motivation was significant, $r=-0.52, p=0.015$. Thus, greater Desire to Gamble under AMPH coincided with faster RT to Gambling words under AMPH. The correlation between the two alcohol indices was not significant, $p>0.18$.

\section{DISCUSSION}

\section{Background and Predictions}

The literature on problem gambling suggests that gambling can induce effects that closely resemble a psychostimulant drug effect. Accordingly, it was predicted that AMPH would activate or prime motivation to gamble in problem gamblers.

\section{Self-Report Data ${ }^{6}$}

The self-report findings provide a consistent pattern of evidence that AMPH primed gambling motivation. The drug significantly increased mean Desire to Gamble in Group $G$ and significantly reduced mean Confidence to Resist Gambling in both Groups G and GD. In addition, the severity of problem gambling, as indexed by Max-Loss, significantly predicted the magnitude of $\mathrm{AMPH}$-induced Desire to Gamble.

The idea that gambling and AMPH induce similar experiences implies that degree of problem gambling should predict positive subjective effects of the drug as well as motivation to experience the drug again. In line with this reasoning, problem gambling severity was positively correlated with AMPH-based ratings of Good Effects and Liking and negatively correlated with ratings of Disliking. Severity of problem gambling also predicted AMPH-based ratings of Desire to Take Again. In other words, the rated reinforcing efficacy of a psychostimulant drug was directly linked to severity of problem gambling. AMPH did not significantly alter mean Desire for Alcohol in Group D or mean Confidence to Resist Alcohol in Groups D or GD. In addition, there were no significant correlations between problem drinking severity and any positive subjective or motivational effects of AMPH.

AMPH did increase mean Desire for Alcohol in the GamblerDrinker group. In the context of the present pattern of evidence it seems most parsimonious to view this finding

\footnotetext{
${ }^{6}$ Throughout the discussion all effects of AMPH are stated relative to placebo and all correlational analyses control for placebo.
} 
as an indication of an adjunctive response that is secondarily activated by a gambling-like state induced by the drug. In other words, comorbid problem gamblerdrinkers often drink while gambling (Baron and Dickerson, 1999), so that a gambling-like experience should activate an association to drink.

The self-report data indicate that Drinkers found some of the subjective effects of AMPH unpleasant. In Group D, AMPH induced a significant increase in ratings of Bad Effects. In addition, higher scores on measures of problem drinking predicted lower AMPH-based ratings of Good Effects, Liking, and Desire to Take Again. This pattern of findings relating to alcohol contrasts markedly with the pattern of findings relating to gambling.

\section{Lexical Salience Task and AMPH-Induced Semantic Activation}

The Lexical Salience Task provided an assessment of AMPH's activation of motivationally relevant and irrelevant (Neutral) semantic domains. Cognitive tasks such as this provide an objective index of processes that are executed automatically, that is, effortlessly (Hasher and Zacks, 1979). Such responses are less susceptible to 'voluntary' factors like experimental demand or Ss' beliefs regarding appropriate behavior (see McKenna and Lewis, 1994).

AMPH is a potent psychomotor stimulant and has been shown to induce faster reaction times across a wide range of cognitive tasks (Hamilton et al, 1983; McKetin et al, 1999; Servan-Schreiber et al, 1998). Considering simply its generic stimulant properties, AMPH would be expected to induce faster reading speed irrespective of the type of stimulus. This is precisely the pattern of data that was displayed by Nongamblers ( $\mathrm{Ss}$ in Groups $\mathrm{D}$ and $\mathrm{C}$ ). AMPH produced a statistically equivalent speeding of reading across all fiveword classes.

By contrast, in Gamblers (Ss in Groups G and GD), AMPH selectively facilitated reading speed to Gambling words while concurrently slowing reading to Neutral words. These effects, which are incongruent with the drug's generic stimulant effects, are directly congruent with an analysis based on primed motivation to gamble.

The activation or priming of an incentive motivational system operates to suppress other motivational systems as well as irrelevant activities and cues (Konorski, 1967; Kostowski, 2002). In Robinson and Berridge's (1993, 2001) model of addiction, incentive motivation is dysregulated by repeated exposure to addictive substances, which results in pathological 'wanting' or craving. As a corollary to this model, Kostowski (2002) proposed that such pathological drug 'wanting' involves concurrent pathological suppression of irrelevant activities and these combined factors mediate compulsive drug seeking to the exclusion of normal adaptive behaviors. This general framework makes sense of the present findings. The self-report data show that AMPH had primed incentive motivation to gamble in these Ss. Thus, the selective speeding to Gambling words can be interpreted as targeted wanting, while the concurrent slowing to Neutral words reflects linked suppression of irrelevant stimuli.

From a clinical perspective, the pattern of findings displayed by gamblers could be viewed as an experimental analog of a gambling-centered preoccupation. Activation of semantic networks has also been found to skew drug-related decisions (Weingardt et al, 1996; Weinstein et al, 2000; Zack et al, 1999) and drug-seeking behavior (Stein et al, 2000). Thus, the pattern of cognitive activation observed in gamblers under AMPH would be expected to skew decisions toward more gambling (eg 'play another round') and to suppress gambling-irrelevant, adaptive behaviors (eg go home).

Correlational analyses revealed that problem gambling severity directly predicted the degree of drug-induced improvement in reading speed to Gambling words as well as the slowing of reading to Neutral words. This indicates that the polarizing effects of AMPH on access to gamblingrelated $v s$ unrelated concepts is linked to gambling pathology. Also, self-reported Desire to Gamble significantly predicted reading speed to Gambling words under AMPH. This provides statistical evidence that the two procedures were assessing two dimensions of the same phenomenon.

The finding that AMPH primes gambling motivation is consistent with the animal literature on cross-priming, in which a dose of one psychoactive drug primes selfadministration of another drug (Petry, 1997; Schenk and Partridge, 1999; Ulm et al, 1995). Cross-priming has often been investigated within a reinstatement paradigm; this refers to the resumption of a previously extinguished drugseeking response by noncontingent exposure to the priming drug (Shalev et al, 2002; Stewart and de Wit, 1987). The precise mechanisms that mediate cross-priming and reinstatement are complex (Schenk and Partridge, 1999; Shalev et al, 2002; Spealman et al, 1999). Nonetheless, the occurrence of cross-priming can be viewed as evidence that the two drugs affect common neurochemical substrates that are functionally related to the incentive-motivational properties of the two drug reinforcers.

In contrast to the case for gambling, there was little evidence that AMPH directly primed motivation for alcohol in problem drinkers on either the self-report or cognitive indices. Hence the present findings in gamblers cannot be attributed to a generic ability of AMPH to activate addictive motivation. However, it should be noted that the relationship between the subjective effects of AMPH and alcohol appears to be complex.

A recent within-subjects study in healthy volunteers assessed individual differences in response to alcohol and AMPH (Holdstock and de Wit, 2001). In a correlational analysis, Ss who reported pronounced stimulant-like effects of alcohol $(0.8 \mathrm{~g} / \mathrm{kg})$ also reported some greater stimulantlike effects of AMPH $(20 \mathrm{mg})$. These findings suggest some commonalities in the subjective effects of moderate doses of alcohol and AMPH in nonproblem drinkers. The relationship between the subjective effects of alcohol and AMPH in problem drinkers remains to be determined.

AMPH is a potent, unconditioned dopamine agonist (Furmidge et al, 1991; Gold et al, 1989). Panksepp (1998) has proposed that activation of the mesolimbic dopamine system gives rise to an incentive state (ie 'seeking') that involves affective processes which invigorate search behavior ( $p$ 152). This formulation provides an explanatory framework for problem gamblers' heightened readiness to detect gambling words under AMPH in the present study. 
The present findings may also relate to previous research on dopaminergic modulation of semantic memory networks. In a conventional semantic priming paradigm with no motivationally relevant words, L-dopa led to a small but significant slowing of RT to target words that were peripherally related to their respective (verbal) primes in healthy volunteers (Kischka et al, 1996). These investigators argued that 'dopamine increases the signal-to-noise ratio in semantic networks by reducing the spread of semantic processing, thereby leading to a focusing of activation' ( $p$ 1107). The slowing of RT to motivationally irrelevant, neutral words by AMPH in the two subgroups of problem gamblers is suggestive of such a dopaminergic modulating effect. However, although AMPH is primarily associated with dopamine activation, the drug also engages other neurochemical systems (see Brauer et al, 1997). Therefore, the present findings for gamblers cannot be exclusively attributed to dopamine activation.

\section{Limitations}

This study had a number of limitations. For one, the size and diversity of the groups was modest. As well, diagnoses of clinical depression or ADHD were exclusionary criteria. There is a high comorbidity with each of these factors and problem gambling (Potenza et al, 2001; Specker et al, 1995). Moreover, each of these disorders involves disturbances in neurochemical systems activated by psychostimulant drugs (Brown and Gershon, 1993; Solanto, 2002). Therefore, it remains to be determined if the present findings extend to such cases.

\section{Summary and Conclusions}

This study provides an internally consistent pattern of evidence that AMPH primes motivation to gamble in problem gamblers, as indexed both by self-report and by rapid reading performance. In addition to the mean effects, there was a consistent pattern of correlational evidence that the severity of problem gambling predicted the positive subjective and motivational effects of AMPH as well as the drug's effects on access to motivationally relevant and irrelevant semantic domains. In short, the findings provide experimental evidence that neurochemical activation, similar to that engaged by psychostimulant drugs, is an important component of gambling addiction.

\section{Future Directions and Methodology}

The present findings raise important questions about the potential role of other neurochemical systems in problem gambling. In particular, opiate addiction shares significant common mechanisms with psychostimulant addiction (eg Bozarth, 1986; Vanderschuren et al, 1999). In addition, the finding that the opioid antagonist naltrexone can be beneficial in the treatment of problem gamblers (Grant and Kim, 2002) underscores the importance of investigating the role of the opioid system in problem gambling.

The study also highlights important methodological issues. The present assessment utilized two distinct procedures: cognitively 'effortful' self-report and automatically executed rapid reading responses. The two procedures provided evidence that was mutually consistent and complementary. The Lexical Salience Task proved particularly valuable for assessing AMPH-induced activation and inhibition of diverse semantic domains. The finding that, in gamblers, a stimulant drug-like AMPH slowed gamblingunrelated responses while speeding gambling-related ones was counter-intuitive. This finding provides clear evidence for an important but often overlooked dimension of addictive motivation, namely, the inhibition of motivationally irrelevant alternative activities (Goldstein and Volkow, 2002). Inclusion of similar procedures could be valuable in research aimed at identifying and assessing potential medications for the treatment of pathological gambling.

\section{ACKNOWLEDGEMENTS}

We thank Tracy Woodford for her invaluable assistance in carrying out the study and Ken Seergobin for programming the Lexical Salience Task. This research was supported by a grant from the National Center for Responsible Gaming.

\section{REFERENCES}

Annis HM, Graham JM (1988). Situational Confidence Questionnaire (SCQ 39). Addiction Research Foundation: Toronto.

Baron E, Dickerson MG (1999). Alcohol consumption and selfcontrol of gambling behaviour. J Gambling Stud 15: 3-15.

Battig WF, Montague WE (1969). Category norms for verbal items in 56 categories: a replication and extension of the Connecticut category norms. J Exp Psychol Monogr 80(3 Part 2): 1-48.

Beck AT, Beck RW (1972). Screening depressed patients in family practice. A rapid technique. Postgrad Med 52: 81-85.

Bergh C, Eklund T, Sodersten P, Nordin C (1997). Altered dopamine function in pathological gambling. Psychol Med 27: 473-475.

Boerngen-Lacerda R, Souza-Formigoni ML (2000). Does the increase in locomotion induced by ethanol indicate its stimulant or anxiolytic properties? Pharmacol Biochem Behav 67: 225-232.

Bower GH (1981). Mood and memory. Am Psychol 36: 129-148.

Bozarth MA (1986). Neural basis of psychomotor stimulant and opiate reward: evidence suggesting the involvement of a common dopaminergic system. Behav Brain Res 22: 107-116.

Bradley B, Mathews A (1983). Negative self-schemata in clinical depression. Br J Clin Psychol 22: 173-181.

Brauer LH, Ambre J, de Wit H (1996). Acute tolerance to subjective but not cardiovascular effects of D-amphetamine in normal, healthy men. J Clin Psychopharmacol 16: 72-76.

Brauer LH, Goudie AJ, de Wit H (1997). Dopamine ligands and the stimulus effects of amphetamine: animal models versus human laboratory data. Psychopharmacology 130: 2-13.

Brown AS, Gershon S (1993). Dopamine and depression. J Neural Transm Gen Sect 91: 75-109.

Cornell CE, Rodin J, Weingarten H (1989). Stimulus-induced eating when satiated. Physiol Behav 45: 695-704.

de Wit H, Enggasser JL, Richards JB (2002). Acute administration of D-amphetamine decreases impulsivity in healthy volunteers. Neuropsychopharmacology 27: 813-825.

de Wit H, Stewart J (1981). Reinstatement of cocaine-reinforced responding in the rat. Psychopharmacology 75: 134-143.

Dickerson M, Hinchy J, Fabre J (1987). Chasing, arousal and sensation seeking in off-course gamblers. $\mathrm{Br} J$ Addict 82: 673-680.

Druhan JP, Fibiger HC, Phillips AG (1991). Influence of some drugs of abuse on the discriminative stimulus properties of amphetamine. Behav Pharmacol 2: 391-403. 
Duarte C, Biala G, Le Bihan C, Hamon M, Thiebot MH (2003). Respective roles of dopamine D2 and D3 receptors in foodseeking behaviour in rats. Psychopharmacology 166: 19-32.

Ellis HC, Hunt RR (1993). Fundamentals of Cognitive Psychology 5th edn Brown \& Benchmark: Madison, WI. 409pp.

Eysenck HJ, Eysenck SBG (1963). The Eysenck Personality Inventory. Educational and Industrial Testing Service: San Diego.

Furmidge LJ, Exner M, Clark D (1991). Role of dopamine D1 and D2 receptors in mediating the D-amphetamine discriminative cue. Eur J Pharmacol 202: 191-199.

Gold LH, Geyer MA, Koob GF (1989). Neurochemical mechanisms involved in behavioral effects of amphetamines and related designer drugs. NIDA Res Monogr 94: 101-126.

Goldstein RZ, Volkow ND (2002). Drug addiction and its underlying neurobiological basis: neuroimaging evidence for the involvement of the frontal cortex. Am J Psychiatry 159: $1642-1652$.

Grant JE, Kim SW (2002). Effectiveness of pharmacotherapy for pathological gambling: a chart review. Ann Clin Psychiatry 14: 155-161.

Haertzen CA (1965). Addiction Research Center Inventory (ARCI): development of a general drug estimation scale. J Nerv Ment Dis 141: 300-307.

Halladay AK, Wagner GC, Hsu T, Sekowski A, Fisher H (1999). Differential effects of monoaminergic agonists on alcohol intake in rats fed a tryptophan-enhanced diet. Alcohol 18: 55-64.

Hamilton MJ, Smith PR, Peck AW (1983). Effects of bupropion, nomifensine and dexamphetamine on performance, subjective feelings, autonomic variables and electroencephalogram in healthy volunteers. Br J Clin Psychol 15: 367-374.

Hasher L, Zacks RT (1979). Automatic and effortful processes in memory. J Exp Psychol Gen 108: 356-388.

Heishman SJ, Henningfield JE (1991). Discriminative stimulus effects of d-amphetamine, methylphenidate, and diazepam in humans. Psychopharmacology 103: 436-442.

Hickey JE, Haertzen CA, Henningfield JE (1986). Simulation of gambling responses on the Addiction Research Center Inventory. Addict Behav 11: 345-349.

Holdstock L, de Wit $\mathrm{H}$ (1998). Individual differences in the biphasic effects of alcohol. Alcohol Clin Exp Res 22: 1903-1911.

Holdstock L, de Wit H (2001). Individual differences in responses to ethanol and D-amphetamine: a within-subject study. Alcohol Clin Exp Res 25: 540-548.

Hubbell CL, Marglin SH, Spitalnic SJ, Abelson ML, Wild KD, Reid LD (1991). Opioidergic, serotonergic, and dopaminergic manipulations of rats' intake of a sweetened alcoholic beverage. Alcohol 8: 355-367.

Ibanez A, Blanco C, de Castro IP, Fernandex-Piqueras J, Saiz-Ruiz J (2003). Genetics of pathological gambling. J Gambling Stud 19: 11-22.

Jackson A, Stephens DN, Duka T (2003). Lorazepam substitutes for the alcohol stimulus in social drinkers. Psychopharmacology 166: 181-187.

King AC, Houle T, de Wit H, Holdstock L, Schuster A (2002). Biphasic alcohol response differs in heavy versus light drinkers. Alcohol Clin Exp Res 26: 827-835.

Kischka U, Kammer T, Maier S, Weisbrod M, Thimm M, Spitzer M (1996). Dopaminergic modulation of semantic network activation. Neuropsychologia 34: 1107-1113.

Knuston B, Fong GW, Adams CM, Varner JL, Hommer D (2001). Dissociation of reward anticipation and outcome with eventrelated fMRI. Neuroreport 12: 3683-3687.

Konorski J (1967). Integrative Activity of the Brain. University of Chicago Press: Chicago. 531pp.

Kostowski W (2002). Drug addiction as drive satisfaction ('antidrive') dysfunction. Acta Neurobiol Exp 62: 111-117.
Kostowski W, Bienkowski P (1999). Discriminative stimulus effects of ethanol: neuropharmacological characterization. Alcohol 17: 63-80.

Krystal JH, Webb E, Cooney N, Kranzler HR, Charney DS (1994). Specificity of ethanollike effects elicited by serotonergic and noradrenergic mechanisms. Arch Gen Psychiatry 51: 898-911.

Ladouceur R, Gaboury A, Bujold A, Lachance N, Tremblay S (1991). Ecological validity of laboratory studies of videopoker gaming. J Gambling Stud 7: 109-116.

Ladouceur R, Mayrand M, Tourigny Y (1987). Risk taking behavior in gamblers and non-gamblers during prolonged exposure. J Gambling Behav 3: 115-122.

Ladouceur R, Tourigny Y, Mayrand M (1986). Familiarity, group exposure and risking behavior in gambling. J Psychol 120: 45-49.

Le AD, Quan B, Juzytch W, Fletcher PJ, Joharchi N, Shaham Y (1998). Reinstatement of alcohol-seeking by priming injections of alcohol and exposure to stress in rats. Psychopharmacology 135: 169-174.

Leri F, Stewart J (2001). Drug-induced reinstatement to heroin and cocaine seeking: A rodent model of relapse in polydrug use. Exp Clin Psychopharmacol 9: 297-306.

Lesieur HR, Blume SB (1987). The South Oaks Gambling Screen (SOGS): a new instrument for the identification of pathological gamblers. Am J Psychiatry 144: 1184-1188.

Linseman MA (1990). Effects of dopaminergic agents on alcohol consumption by rats in a limited access paradigm. Psychopharmacology 100: 195-200.

Loba P, Stewart SH, Klein RM, Blackburn JR (2001). Manipulations of the features of standard video lottery terminal (VLT) games: effects in pathological and non-pathological gamblers. J Gambling Stud 17: 297-320.

Lynch WJ, Heaser WA, Carroll ME (1998). Effects of amphetamine, butorphanol, and morphine pretreatment on the maintenance and reinstatement of cocaine-reinforced responding. Exp Clin Psychopharmacol 6: 255-263.

Mackey WB, van der Kooy D (1985). Neuroleptics block the positive reinforcing effects of amphetamine but not of morphine as measured by place conditioning. Pharmacol Biochem Behav 22: 101-105.

Martin CS, Earlywine M, Musty RE, Perrine MW, Swift RM (1993). Development and validation of the Biphasic Alcohol Effects Scale. Alcohol Clin Exp Res 17: 140-146.

Maurel S, Schreiber R, De Vry J (1997). Substitution of the selective serotonin reuptake inhibitors fluoxetine and paroxetine for the discriminative stimulus effects of ethanol in rats. Psychopharmacology 130: 404-406.

McCusker CG, Gettings B (1997). Automaticity of cognitive biases in addictive behaviours: further evidence with gamblers. $\mathrm{Br} J$ Clin Psychol 36: 543-554.

McKenna FP, Lewis C (1994). A speech rate measure of laboratory induced affect: the role of demand characteristics revisited. $\mathrm{Br} J$ Clin Psychol 33: 345-351.

McKetin R, Ward PB, Catts SV, Mattick RP, Bell JR (1999). Changes in auditory selective attention and event-related potentials following oral administration of $\mathrm{D}$-amphetamine in humans. Neuropsychopharmacology 21: 380-390.

Mogg K, Bradley BP, Millar N, White J (1995). A follow-up study of cognitive bias in generalized anxiety disorder. Behav Res Ther 33: 927-935.

Moreno I, Saiz-Ruiz J, Lopez-Ibor JJ (1991). Serotonin and gambling dependence. Human Psychopharmacol 6(Suppl): S9-S12.

Neely JH (1991). Semantic priming effects in visual word recognition: A selective review of current findings and theories. In: Besner D, Humphreys GW (eds). Basic Processes in Reading: Visual Word Recognition. Erlbaum: Hillsdale, NJ. pp 264-337. 
Panksepp J (1998). Affective Neuroscience: The Foundations of Human and Animal Emotions. Oxford University Press: New York. 466pp.

Petry NM (1997). Benzodiazepine-GABA modulation of concurrent ethanol and sucrose reinforcement in the rat. Exp Clin Psychopharmacol 5: 183-194.

Potenza MN (2001). The neurobiology of pathological gambling. Semin Clin Neuropsychiatry 6: 217-226.

Potenza MN, Steinberg MA, McLaughlin SD, Wu R, Rounsaville BJ, O'Malley SS (2001). Gender-related differences in the characteristics of problem gamblers using a gambling helpline. Am J Psychiatry 158: 1500-1505.

Ranaldi R, Anderson KG, Carroll FI, Woolverton WL (2000). Reinforcing and discriminative stimulus effects of RTI 111, a 3phenyltropane analog in rhesus monkeys: interaction with methamphetamine. Psychopharmacology 153: 103-110.

Ridley RM, Baker HF, Frith CD, Dowdy J, Crow TJ (1988). Stereotyped responding on a two-choice guessing task by marmosets and humans treated with amphetamine. Psychopharmacology 95: 560-564.

Robinson TE, Berridge KC (1993). The neural basis of drug craving: an incentive-sensitization theory of addiction. Brain Res Rev 18: 247-291.

Robinson TE, Berridge KC (2001). Incentive sensitization and addiction. Addiction 96: 103-114.

Ross HE, Gavin DR, Skinner HA (1990). Diagnostic validity of the MAST and the alcohol dependence scale in the assessment of DSM-III alcohol disorders. J Stud Alcohol 51: 506-513.

Roy A, Adinoff B, Roehrich L, Lamparski D, Custer D, Lorenz V et al (1988). Pathological gambling. A psychobiological study. Arch Gen Psychiatry 45: 369-373.

Samson HH, Chappell A, Slawecki C, Hodge C (1999). The effects of microinjection of $\mathrm{D}$-amphetamine into the $\mathrm{n}$. accumbens during the late maintenance phase of an ethanol consumption bout. Pharmacol Biochem Behav 63: 159-165.

Sasaki JE, Tatham TA, Barrett JE (1995). The discriminative stimulus effects of methamphetamine in pigeons. Psychopharmacology 120: 303-310.

Schechter MD, Lovano DM (1982). Time course of action of ethanol upon a stimulant-depressant continuum. Arch Int Pharmacodyn Ther 260: 189-195.

Schenk S, Partridge B (1999). Cocaine-seeking produced by experimenter-administered drug injections: dose-effect relationships in rats. Psychopharmacology 147: 285-290.

Schneider W (1988). MicroExperimental Laboratory: an integrated system for IBM PC compatibles. Behav Res Meth Instr Comp 20: 206-217.

Schuckit MA, Greenblatt D, Gold E, Irwin M (1991). Reactions to ethanol and diazepam in healthy young men. J Stud Alcohol 52: $180-187$.

Self DW, Nestler EJ (1998). Relapse to drug-seeking: neural and molecular mechanisms. Drug Alcohol Depend 51: 49-60.

Servan-Schreiber D, Carter CS, Bruno RM, Cohen JD (1998). Dopamine and the mechanisms of cognition: Part II. Damphetamine effects in human subjects performing a selective attention task. Biol Psychiatry 43: 723-729.

Shacham S (1983). A shortened version of the Profile of Mood States. J Pers Assess 47: 305-306.

Shaham Y, Stewart J (1996). Effects of opioid and dopamine receptor antagonists on relapse induced by stress and reexposure to heroin in rats. Psychopharmacology 125: 385-391.

Shalev U, Grimm JW, Shaham Y (2002). Neurobiology of relapse to heroin and cocaine seeking: a review. Pharmacol Rev 54: $1-42$.

Shelton KL, Grant KA (2002). Discriminative stimulus effects of ethanol in C57BL/6J and DBA/2J inbred mice. Alcohol Clin Exp Res 26: 747-757.
Skinner HA (1982). The drug abuse screening test. Addict Behav 7: 363-371.

Sobell LC, Sobell MB (1992). Timeline Followback: a technique for assessing self-reported alcohol consumption. In: Litten RZ, Allen J (eds). Measuring Alcohol Consumption: Psychosocial and Biological Methods. Humana: Totowa, NJ. pp 41-72.

Solanto MV (2002). Dopamine dysfunction in AD/HD: integrating clinical and basic neuroscience research. Behav Brain Res 130: $65-71$.

Spealman RD, Barrett-Larimore RL, Rowlett JK, Platt DM, Khroyan TV (1999). Pharmacological and environmental determinants of relapse to cocaine-seeking behavior. Pharmacol Biochem Behav 64: 327-336.

Specker SM, Carlson GA, Christenson GA, Marcotte M (1995). Impulse control disorders and attention deficit disorder in pathological gamblers. Ann Clin Psychiatry 7: 175-179.

Spyraki C, Fibiger HC, Phillips AG (1982). Dopaminergic substrates of amphetamine-induced place preference conditioning. Brain Res 253: 185-193.

Stanovich KE, West RF (1983). On priming by a sentence context. $J$ Exp Psychol Gen 112: 1-36.

Stein KD, Goldman MS, Del Boca FK (2000). The influence of alcohol expectancy priming and mood manipulation on subsequent alcohol consumption. J Abnorm Psychol 109: 106-115.

Stetter F, Ackermann K, Bizer A, Straube ER, Mann K (1995). Effects of disease-related cues in alcoholic inpatients: results of a controlled 'Alcohol Stroop' study. Alcohol Clin Exp Res 19: 593-599.

Stewart J, de Wit H (1987). Reinstatement of drug-taking behavior as a method of assessing incentive motivational properties of drugs. In: Bozarth MA (ed). Methods of Assessing the Reinforcing Properties of Abused Drugs. Springer-Verlag: New York. pp 211-227.

Stolerman IP, Olufsen K (2001). Generalisation of ethanol with drug mixtures containing a positive modulator of the GABA (A) receptor and an NMDA antagonist. Neuropharmacology 40: 123-130.

Ulm RR, Volpicelli JR, Volpicelli LA (1995). Opiates and alcohol self-administration in animals. J Clin Psychiatry 56(Suppl 7): 5-14.

Vanderschuren LJ, Schoffelmeer AN, Mulder AH, De Vries TJ (1999). Dopaminergic mechanisms mediating the long-term expression of locomotor sensitization following pre-exposure to morphine or amphetamine. Psychopharmacology 143: 244-253.

Volkow ND, Fowler JS, Wang GJ, Goldstein RZ (2002). Role of dopamine, the frontal cortex and memory circuits in drug addiction: insights from imaging studies. Neurobiol Learn Mem 78: $610-624$.

Walsh JK, Humm T, Muehlbach MJ, Sugerman JL, Schweitzer PK (1991). Sedative effects of ethanol at night. J Stud Alcohol 52: 597-600.

Weingardt KR, Stacy AW, Leigh BC (1996). Automatic activation of alcohol concepts in response to positive outcomes of alcohol use. Alcohol Clin Exp Res 20: 25-30.

Weinstein AM, Feldtkeller BT, Law F, Myles J, Nutt DJ (2000). The processing of automatic thoughts of drug use and craving in opiate-dependent individuals. Exp Clin Psychopharmacol 8: 549-553.

Winer BJ (1971). Statistical Principles in Experimental Design 2nd edn McGraw-Hill: New York. 907pp.

Yokel RA, Wise RA (1978). Amphetamine-type reinforcement by dopaminergic agonists in the rat. Psychopharmacology 58: 289-296.

Zack M, Toneatto T, MacLeod CM (1999). Implicit activation of alcohol concepts by negative affective cues distinguishes 
between problem drinkers with high and low psychiatric distress. J Abnorm Psychol 108: 518-531.

Zacny JP, Bodker BK, de Wit H (1992). Effects of setting on the subjective and behavioral effects of d-amphetamine in humans. Addict Behav 17: 27-33.

Zuckerman M, Lubin B (1965). Multiple Affect Adjective Checklist. Educational and Industrial Testing Service: San Diego.

\section{APPENDIX}

\section{WORD STIMULI FOR LEXICAL SALIENCE TASK}

Gambling: ace bet bingo blackjack cards cash casino chips dealer dice gamble game jackpot keno lottery lotto luck odds payoff player poker races risk roulette score slots stakes track wager winner
Alcohol: alcohol ale beer bender blitzed bombed booze bottle bourbon brandy buzz cocktail drink gin hammered lager liquor loaded rum rye scotch shooter smashed tavern tipsy vodka wasted whiskey wine wrecked

Positive affect: alert aroused bliss bold brave calm clever courage daring ecstasy exciting fun hopeful joy keen lively loving pep powerful quick rush sexy skillful smart strong thrill upbeat vigorous warm witty

Negative affect: angry anxious beaten confused dizzy dread fail grouchy guilty helpless hopeless hurt insane lonely misery nasty nervous outcast panic sad shaky shame sick stress tense unhappy upset uptight weak worry

Neutral: arch boiler brick buttress cabinet cable carpet chute clock closet doorway duct garage gate landing latch lattice outlet patio pillar platform rafter railing roof sink stairs step trough window wing 